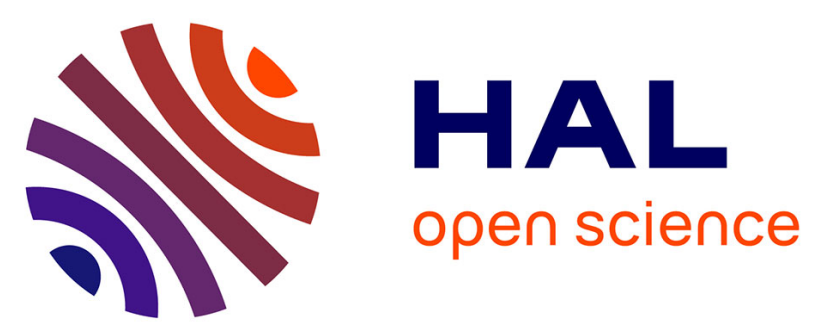

\title{
Do Patients' Perceptions of Leg Length Correlate With Standing 2- and 3-Dimensional Radiographic Imaging?
}

Jean-Yves Lazennec, Adrien Brusson, Marc-Antoine Rousseau, Christopher B. Robbins, Aidin Eslam Pour

\section{- To cite this version:}

Jean-Yves Lazennec, Adrien Brusson, Marc-Antoine Rousseau, Christopher B. Robbins, Aidin Eslam Pour. Do Patients' Perceptions of Leg Length Correlate With Standing 2- and 3Dimensional Radiographic Imaging?. The Journal of Arthroplasty, 2016, 31 (10), pp.2308-2313. 10.1016/j.arth.2016.03.065 . hal-02482423

\section{HAL Id: hal-02482423 \\ https://hal.science/hal-02482423}

Submitted on 18 Feb 2020

HAL is a multi-disciplinary open access archive for the deposit and dissemination of scientific research documents, whether they are published or not. The documents may come from teaching and research institutions in France or abroad, or from public or private research centers.
L'archive ouverte pluridisciplinaire HAL, est destinée au dépôt et à la diffusion de documents scientifiques de niveau recherche, publiés ou non, émanant des établissements d'enseignement et de recherche français ou étrangers, des laboratoires publics ou privés. 


\title{
Do Patients' Perceptions of Leg Length Correlate With Standing 2- and 3-Dimensional Radiographic Imaging?
}

\author{
Jean Y. Lazennec, MD, PhD a, b, c, Adrien Brusson, MS c, Marc A. Rousseau, MD b, c, d, \\ Christopher B. Robbins, $\mathrm{PhD}^{\mathrm{e}}$, Aidin Eslam Pour, MD ${ }^{\mathrm{e}, *}$ \\ ${ }^{a}$ Department of Orthopaedic and Trauma Surgery, Pitié-Salpêtrière Hospital, Assistance Publique-Hopitaux de Paris, UPMC, Paris, France \\ ${ }^{\mathrm{b}}$ Biomechanics Lab (LBM), Arts et Metiers Paris-Tech, Paris, France \\ ${ }^{\mathrm{c}}$ Department of Anatomy, UPMC, Paris, France \\ d Department of Orthopaedic and Trauma Surgery, Avicenne hospital, Assistance Publique-Hopitaux de Paris, Bobigny, France \\ e Department of Orthopaedic Surgery, University of Michigan, Ann Arbor, Michigan
}

Level of Evidence:

level-IV diagnostic case series

Keywords:

leg length

three-dimensional radiography

knee alignments

arthroplasty

femur

tibia

\section{A B S T R A C T}

Background: This study compared 2- and 3-dimensional (2D and 3D) radiographic measurements of anatomical and functional leg length and knee coronal and sagittal alignments and correlated these measurements with patients' leg-length perceptions.

Methods: Patients without symptomatic spinal pathology, previous surgery of the spine, and lower extremities (140 lower extremities) were evaluated on EOS images obtained in standing position. Numerous measurements of each limb were compared to the contralateral limb. All 2D/3D measures were evaluated and compared for repeatability and reproducibility.

Results: Mean 2D functional and anatomical lengths were $78.7 \mathrm{~cm}$ (64.7-88.4, confidence interval [CI] 95\%: 77.4-80) and 78.3 cm (64.9-87.9, CI 95\%: 77-79.6), respectively. Mean 3D functional and anatomical lengths were $78.9 \mathrm{~cm}(65.1-88.7, \mathrm{CI} 95 \%$ : 77.6-80.2) and 78.9 cm (65.6-88.3, CI 95\%: 77.8-80.5), respectively $(P<.001)$. Mean 2D and 3D knee varus/valgus angles were $-1.9^{\circ}$ ( -26.4 to $9.1, \mathrm{CI} 95 \%$ : -3.5 to -0.7 ) and $-0.9^{\circ}$ ( -19.2 to 11.8, CI 95\%: -2.4 to 0.2$)$, respectively $(P=.004)$. Multiple regression analysis found that patients with $>10^{\circ}$ of flexum/recurvatum were $2.1 \times$ more likely to perceive unequal length $(P<.1)$. Patients with irreducible varus/valgus knee deformity were $4 \times$ more likely to perceive unequal length $(P<.04)$.

Conclusion: EOS imaging allows more accurate assessment of anatomical and functional lengths. Patients' perceptions of lower extremity length may correlate more closely with coronal and sagittal alignments of the knee than with femoral or tibial length. This study highlights the importance of physical examination of all the joints and 3D measurements in functional standing position.
The accurate assessment of leg length is essential for planning the correction of deformities and limb-length discrepancy. Limblength discrepancy is a common finding in degenerative hip and knee disorders and congenital or trauma-related lower extremity deformities. It is also a common postoperative complication after total hip and knee arthroplasty [1-4], which can result in patient dissatisfaction, limping, need for shoe lift, low back pain, hip instability, and revision surgery [5-11]. Limb-length discrepancy can also result in medicolegal complaints. Upadhyay et al. [12] surveyed members of the American Association of Hip and Knee Society regarding medical malpractice litigations. Limb-length discrepancy was the second most common reason for litigation, and $8 \%$ of surgeons had been a defendant in a legal case secondary to this complication.

Most radiographic analyses of arthroplasty patients are based on anteroposterior (AP) radiographs in the standing position and computed tomography (CT) scans in the supine position. Despite its better accuracy, CT measures anatomical length in the supine position but does not evaluate functional length in the standing position, the position in which limb-length discrepancy is perceived by patients. Functional length integrates both the lengths 
of the femoral and tibial bones and the coronal (varus/valgus) and sagittal (genu flexum/recurvatum) knee alignments. It also integrates the spine-pelvis junction and its effect on the pelvic obliquity.

These questions were asked: (1) Do the 2- and 3-dimensional (2D and 3D) radiographic measurements of leg length and knee coronal and sagittal alignments differ substantially? (2) Do patients' perceptions of leg length correlate with the 2D and 3D anatomical and functional limb lengths or knee coronal and sagittal alignments?

Our hypotheses were that the anatomical and functional lengths would differ substantially between the 2D and 3D images and that genu flexum, genu recurvatum, severe varus, and valgus deformities, especially those that are correctable, would affect patient perception of functional leg length more than just anatomical length.

\section{Methods}

This was a nonrandomized, prospective study of the consecutive patients who were assessed with EOS imaging and met our inclusion and exclusion criteria. Patients were recruited in the Department of Orthopaedic and Trauma Surgery, Pitié-Salpêtrière Hospital, between January 2013 and December 2015.

We routinely evaluate all patients in clinic using the EOS imaging system for spine and lower extremity-related pain. The EOS system (EOS imaging SA, Paris, France) is an innovative slotscanning radiograph system allowing the simultaneous acquisition of orthogonal AP and lateral radiographs while the patient is standing, sitting, or even squatting with less irradiation than standard imaging. After obtaining approval from our institutional review board, we reviewed 70 patients for bilateral lower extremity length assessment. We included all patients (aged 18-80 years) who were assessed in our clinic for hip and knee pain due to different degrees of degenerative joint disease. These patients were all treated nonoperatively for degenerative hip or knee pain before EOS imaging. All patients with symptomatic spinal pathology; previous spinal surgery; lower extremity open reduction; and external fixation, osteotomy, or arthroplasty (hip, knee, ankle) were excluded.

Each patient stood comfortably in the EOS machine. The position was specifically checked to avoid superimposition of anatomical structures on the lateral view (which would make 3D reconstruction impossible). We successively used the AP uniplanar acquisition (an equivalent of standard AP long-leg x-ray) and then the biplanar acquisition of the entire lower extremities (Fig. $1 \mathrm{~A}$ and B). The biplanar acquisition was used to perform stereoradiographic 3D modeling of each lower extremity using specialized software (sterEOS 3D, EOS imaging SA) according to a previously described method [13]. The bony landmarks used to determine the femoral and tibial torsions in 3D images were identical to those used in the $2 \mathrm{D}$ measurements. The parameters measured in both $2 \mathrm{D}$ and $3 \mathrm{D}$ views were the hip-knee-ankle (HKA) angle and the femoral and tibial mechanical axes (FMA and TMA). The FMA was defined as the line connecting the center of the femoral head to the center of the femoral notch, and the TMA was defined as the line from the center of the tibial plateau (interspinous intercruciate midpoint) extending distally to the center of the tibial plafond (Fig. 2A and B). HKA angle was defined as the angle between the FMA and TMA. Neutral angle was defined as HKA angle of 0 . The lengths of the femoral and tibial bones and the anatomical and functional lengths of the lower extremity were also measured. Tibial and femoral rotation and knee flexion/hyperextension angle were also derived from the $3 \mathrm{D}$ reconstruction [14].
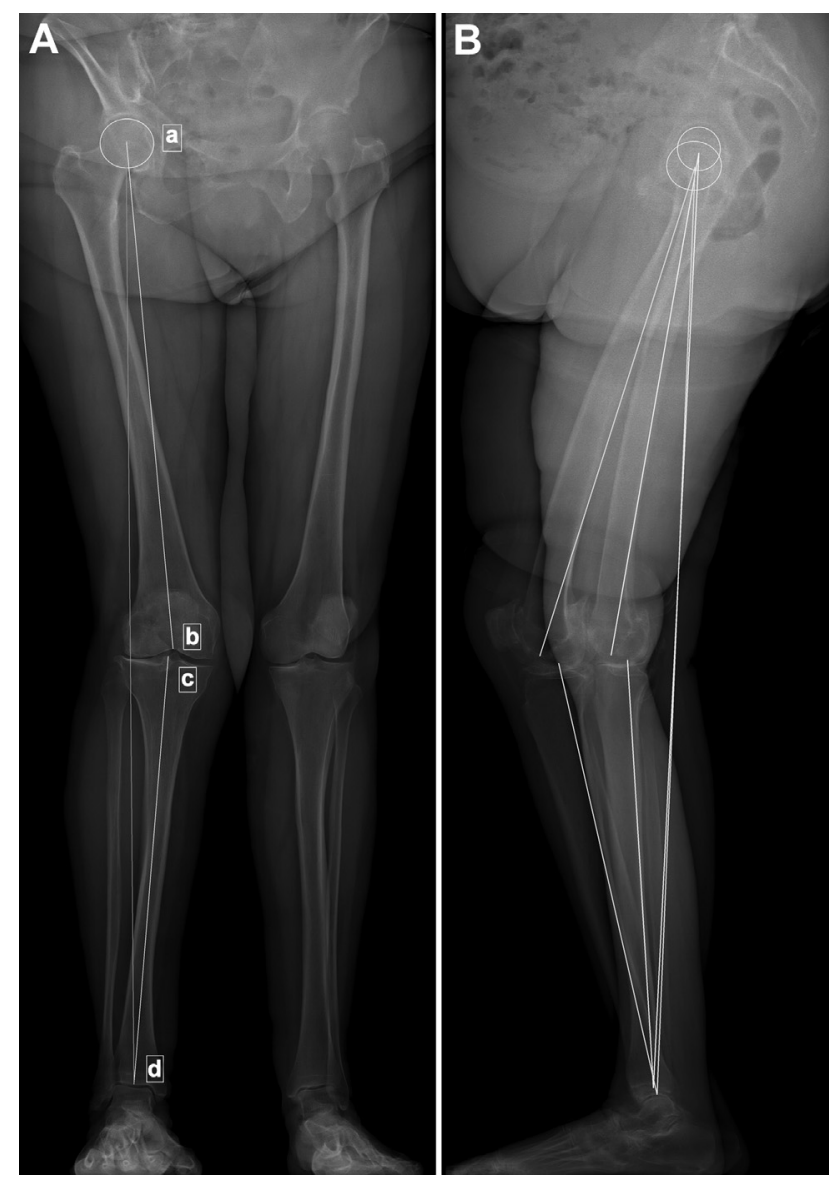

Fig. 1. (A and B) Two dimensional anteroposterior and lateral views of the lower extremity, showing the anatomical length of the femoral (ab) and tibial bones (cd) and the functional length ( $\mathrm{AD}$ line in anteroposterior view and the line connecting the femoral head to ankle in the lateral view).

We used the following definitions (Fig. 1A):

- Anatomical femoral length: distance between the center of the femoral head (a) and the center of the trochlea (b).

- Anatomical tibial length: distance between the center of the tibial spine (intercondylar eminence) (c) and the center of the ankle joint (d).

- Functional length: distance between the center of the femoral head to the center of the ankle joint (ad).

- Anatomical length: sum of the anatomical femoral and tibial lengths $(a b+c d)$.

Previous studies have shown that mean anatomical leg-length difference is about $5 \mathrm{~mm}$ in up to $90 \%$ of the general population. Some of these studies also looked into the clinical significance of the anatomical leg-length discrepancy and considered the threshold to be as low as $5 \mathrm{~mm}$ [15] and as high as $30 \mathrm{~mm}[16,17]$. For this study, legs were considered to be of equal length when the difference between the anatomical and functional lengths of lower extremities was $\leq 5 \mathrm{~mm}$.

All patients were asked if they perceived equal or unequal limb length. The knee coronal angle (varus/valgus) was also assessed during the physical examination by the senior author with manual varus and valgus stress to see if the varus/valgus deformity was correctable to neutral angle or not. This was done using a goniometer, as validated in previously published work [18]. Patients were categorized into 3 groups based on correctability of deformity: completely 

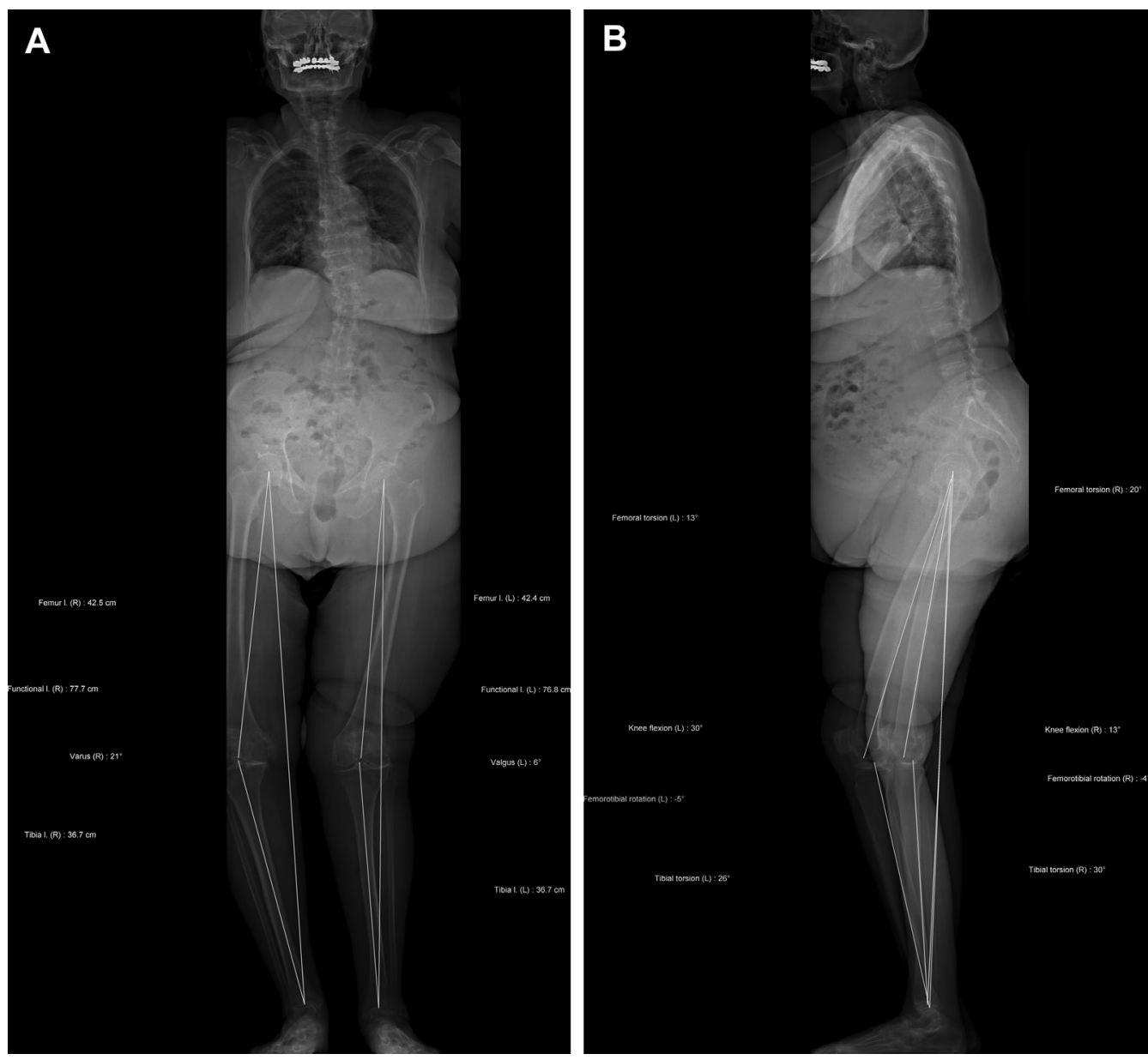

Fig. 2. (A and B) Measurement of the anatomical and functional length of both extremities in anteroposterior and lateral views in a patient.

correctable (within $5^{\circ}$ of the neutral HKA angle), partially correctable (correctable but not within $5^{\circ}$ of the neutral HKA angle), and noncorrectable (unable to change the alignment with manual stress).

\section{Statistical Analysis}

For both the 2D and 3D methods, valgus angulation was considered positive and varus angulation negative. Each patient's 2D and 3D measurements were compared. The statistical analysis was performed with MedCalc (version 11.2.0.0, Mariakerke, Belgium). Along with descriptive statistics, the differences between measurements derived from the 2D and 3D methods were analyzed for repeatability and reproducibility. Student $t$ test was used to determine if HKA angle measurement differed between these 2 methods and to assess the effect of flexion/hyperextension, femoral rotation, and tibial rotation on the $2 \mathrm{D}$ and $3 \mathrm{D}$ measurements. Cohen's Kappa test was used to assess the level of agreement between the patient's perception of limb-length discrepancy and objective measurement of limb length. Logistic regression was used to find any correlation between the patient's perception of the length and objective measurements of the length and different angles of the knee. The significance level was set at $5 \%$.

\section{Results}

The descriptive measurement data are presented in Table 1. The mean 2D functional and anatomical lengths were $78.7 \mathrm{~cm}$ (64.7-88.4, confidence interval [CI] 95\%: 77.4-80) and $78.3 \mathrm{~cm}$
(64.9-87.9, CI 95\%: 77-79.6), respectively. The mean 3D functional and anatomical lengths were $78.9 \mathrm{~cm}$ (65.1-88.7, CI 95\%: 77.6-80.2) and $78.9 \mathrm{~cm}$ (65.6-88.3, CI 95\%: 77.8-80.5), respectively $(P<.001)$. The difference between 2D and 3D functional length measurements is only $2 \mathrm{~mm}$. The difference in 2D and 3D anatomical length measurements is $6 \mathrm{~mm}$.

The mean $2 \mathrm{D}$ knee varus/valgus angle was $-1.9^{\circ}$ ( -26.4 to $9.1, \mathrm{CI}$ 95\%: -3.5 to -0.7$)$. The mean 3D knee varus/valgus angle was $-0.9^{\circ}$ ( -19.2 to $11.8, \mathrm{CI} 95 \%$ : -2.4 to 0.2$)(P=.004)$. There was no substantial difference between the $2 \mathrm{D}$ and $3 \mathrm{D}$ measurements of sagittal knee angle (flexum/recurvatum).

For patient perception of length, 45 of 70 patients $(64.3 \%)$ felt that their lower limb lengths were equal (Table 2). For 2D measurements, functional leg-length discrepancy was $<5 \mathrm{~mm}$ in 37 of 70 patients (52.9\%) and anatomical length discrepancy was $<5 \mathrm{~mm}$ in 40 of 70 patients (57.1\%). For 3D measurements, functional leglength discrepancy was $<5 \mathrm{~mm}$ in 36 of 70 patients (51.4\%) and anatomical length discrepancy was $<5 \mathrm{~mm}$ in 45 of 70 patients (64.3\%). Testing for agreement between patient perception and objective measurement of limb length is presented in Table 3. Interestingly, agreement is better for 2D measurements than for 3D, but the agreement is moderate at best.

In coronal knee angle measurements (Table 1), 35 of 70 patients $(50 \%)$ were within $5^{\circ}$ of neutral angle. Among those who were not, 18 patients were categorized as partially correctable and 17 patients were noncorrectable in physical examination.

For multiple logistic regression analysis, the knees $(n=140)$ were divided into 2 groups on the basis of coronal knee angle 
Table 1

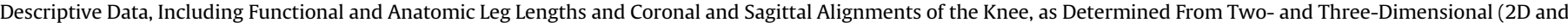
3D) Imaging.

\begin{tabular}{|c|c|c|c|c|c|c|}
\hline Parameters & Mean & Standard Deviation & Minimum & Maximum & $95 \% \mathrm{CI}$ & $P$ Value \\
\hline 2D functional length & 78.7 & 5.5 & 64.7 & 88.4 & $77.4-80$ & $<.001$ \\
\hline 3D functional length & 78.9 & 5.5 & 65.1 & 88.7 & $77.6-80.2$ & \\
\hline 2D anatomical length & 78.3 & 5.4 & 64.9 & 87.9 & 77-79.6 & $<.001$ \\
\hline 3D anatomical length & 78.9 & 5.4 & 65.6 & 88.3 & $77.8-80.5$ & \\
\hline 2D hip-knee-ankle angle & 4.9 & 1.9 & 0.6 & 9.3 & $4.8-5.7$ & .9 \\
\hline 3D hip-knee-ankle angle & 4.9 & 1.5 & 1.8 & 8.4 & 4.6-5.3 & \\
\hline 2D knee varus/valgus & -1.9 & 6.5 & -26.4 & 9.1 & -3.5 to -0.7 & .004 \\
\hline 3D knee varus/valgus & -0.9 & 5.8 & -19.2 & 11.8 & -2.4 to 0.2 & \\
\hline 2D knee flexum/recurvatum & 7.4 & 12 & -14.8 & 46.7 & $4.8-11.5$ & .39 \\
\hline 3D knee flexum/recurvatum & 7.3 & 11.9 & -15.1 & 44.5 & $4.5-10.5$ & \\
\hline
\end{tabular}

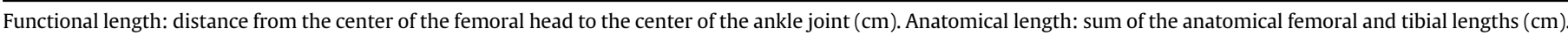
Varus knee angle $\left(^{\circ}\right)$ and genu recurvatum $\left(^{\circ}\right.$ ) are considered negative. Valgus knee angle $\left(^{\circ}\right)$ and genu flexum $\left(^{\circ}\right)$ are considered positive.

$\mathrm{Cl}$, confidence interval.

(varus-valgus): $\pm 5^{\circ}$ from the neutral angle for a first analysis and $\pm 10^{\circ}$ for a second analysis. The knees $(\mathrm{n}=140)$ were also divided into 2 groups on the basis of sagittal knee angle: $\pm 5^{\circ}$ for a first analysis and $\pm 10^{\circ}$ for a second analysis. In simple regression, we found that patient perception of leg length was correlated with flexum-recurvatum angle $>10^{\circ}(P<.0001), 2 \mathrm{D}$ varus/valgus angle $>5^{\circ}(P=.001)$, and 3D varus/valgus angle $>10^{\circ}(P=.009)$. Two and 3D measurements of length were not found to correlate with limblength perception $(P>.1)$. We did not find any correlation between patient perception and femoral torsion $(P=.674)$ and tibial torsion $(P=.992)$. In multiple logistic regression analysis, we found that patients who had $>10^{\circ}$ degrees of flexum/recurvatum were 2.1 times more likely to perceive unequal leg length (95\% CI: $0.9-5$; $P=.09$ ). Those patients who had an uncorrectable varus/valgus knee deformity were 4 times more likely to perceive unequal leg length (95\% CI: $1-15 ; P=.04)$.

Regarding repeatability and reproducibility, interclass correlation coefficients $>0.95$ were found for all measurements except tibial mechanical angle ( 0.91 for $2 \mathrm{D}$ and 0.92 for 3D; Tables 4 and 5).

\section{Discussion}

Leg-length discrepancy is a common finding in degenerative disease of the hip and knee, a common complaint after hip or knee arthroplasty, and sometimes results in costly litigation [19-21]. In one study, $30 \%$ of the patients perceived different leg length after total hip arthroplasty [22] and only $36 \%$ of these patients had a true limb-length discrepancy in imaging studies. This topic has been previously studied, yet much remains to be understood. Patients are aware of limb-length discrepancy in the standing position, but the limb-length discrepancy is mostly assessed by clinical examination in supine position or radiographic studies such as $\mathrm{X}$-ray, $\mathrm{CT}$, and magnetic resonance imaging that are also obtained in supine position. These methods do not take into account the sagittal or coronal knee deformities and their potential correctability or the spinal pathologies and their effect on coronal or sagittal pelvic tilt. The prevalence of anatomical leg-length discrepancy is diversely described in the literature [23-25]. Different authors report an anatomical limb-length discrepancy of $5 \mathrm{~mm}$ or more in $90 \%$ of the population [23-25]. They found that $20 \%$ of their patients had a discrepancy in leg length of $10 \mathrm{~mm}$ or more and $6 \%-8 \%$ had a difference of $14 \mathrm{~mm}$ or more [24-26]. Some of the other factors that could potentially affect the leg-length perception have been assessed, including gender [27-30] and height [27,31]. Factors such as coronal and sagittal knee alignment and its reducibility are not extensively studied.

\section{Agreement of 2D and 3D Measurements of Leg Length and Knee Coronal and Sagittal Alignment}

Most of the previously published studies did not use 3D imaging methods. The reliability of long-leg radiographic techniques such as orthoroentgenogram, scanogram, and computerized digital radiographs may not be very high due to parallax and magnification error or methodologic differences between publications [32]. Our study found that both functional and anatomical leg-length measurements were different between $3 \mathrm{D}$ and $2 \mathrm{D}$ imaging. In all measurements, the mean 3D imaging measurements were higher than the mean 2D measurements. We also found a difference between 2D and 3D measurements of knee coronal alignment (varus/ valgus) and sagittal alignment (genu flexum/recurvatum). The 3D measurements are more accurate due to the consideration of the

Table 2

Comparison of the Variables Between the Patients Who Perceived Equal Leg Length and Those Who Did Not.

\begin{tabular}{|c|c|c|c|c|c|c|c|}
\hline \multirow[t]{2}{*}{ 3D Parameters } & \multicolumn{3}{|c|}{ Perceived Equal Leg Length } & \multicolumn{3}{|c|}{ Did Not Perceive Equal Leg Length } & \multirow[t]{2}{*}{$P$ Value } \\
\hline & Mean & Minimum & Maximum & Mean & Minimum & Maximum & \\
\hline 3D femoral length & 42.5 & 35.4 & 47.3 & 41.9 & 35.2 & 47.3 & .414 \\
\hline 3D tibial length & 41.9 & 35.2 & 47.3 & 36.1 & 30.4 & 41.3 & .791 \\
\hline 3D functional length & 79.5 & 67.5 & 88.7 & 77.7 & 65.1 & 88.2 & .993 \\
\hline 3D anatomical length & 79.4 & 67.1 & 88.2 & 78.1 & 65.6 & 88.3 & .949 \\
\hline 3D coronal knee alignment & -0.5 & -14.1 & 11.8 & -1.6 & -19.2 & 10.7 & .025 \\
\hline 3D knee flexum/recurvatum & 4.3 & -15.1 & 36.2 & 12.6 & -11 & 44.5 & .04 \\
\hline Femoral torsion & 14.9 & -5.3 & 38.8 & 11.8 & -45 & 40 & .07 \\
\hline Tibial torsion & 31.4 & 6.2 & 52.4 & 32.1 & 9.3 & 52.9 & .375 \\
\hline
\end{tabular}

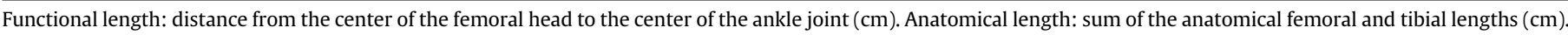
Varus knee angle $\left(^{\circ}\right)$ and genu recurvatum $\left(^{\circ}\right)$ are considered negative. Valgus knee angle $\left(^{\circ}\right)$ and genu flexum $\left({ }^{\circ}\right)$ are considered positive.

3D, three dimensional. 
Table 3

Agreement Between Patients' Perceptions of the Limb Length and Objective Measurements.

\begin{tabular}{llll}
\hline Parameters & $\begin{array}{l}\text { Percentage of } \\
\text { Agreement }\end{array}$ & $\begin{array}{l}\text { Fairness of the } \\
\text { Agreement }\end{array}$ & Kappa Value \\
\hline 2D functional length & 77 & Moderate & 0.535 \\
2D anatomic length & 73 & Moderate & 0.434 \\
3D functional length & 70 & Fair & 0.395 \\
3D anatomic length & 60 & Slight & 0.129 \\
\hline
\end{tabular}

femoral and tibial torsion. This has been shown in other studies. Thelen et al. [33] assessed 2D and 3D images of the knee for the accuracy of the HKA angle. They measured the angle with the knee flexed $0^{\circ}, 9^{\circ}$, and $18^{\circ}$ and found $1.4^{\circ}, 4.7^{\circ}$, and $6.8^{\circ}$ error, respectively, between the 2D and 3D images. Of course, 3D imaging is not available in all centers and it might be more expensive to obtain. The orthopedic surgeons can assess the alignment of the lower extremity during the physical examination and consider 3D imaging in patients with severe malalignment or torsional deformities.

\section{Correlation of Patients' Perceptions of Leg Length With 2D and 3D Imaging}

To the best of our knowledge, no previous studies have assessed the correlation between the perception of limb-length discrepancy and the knee alignment or lower extremity torsion as possible factors influencing individual adaptation. In this study, we have demonstrated the influence of knee frontal and sagittal plane alignment deformities and the impact of the reducibility of these deformities on patient perception of leg length. Many patients who have degenerative hip arthritis also have degenerative knee disease with sagittal or coronal alignment deformity. The odds of having a perception of unequal leg length was 2.1 if patients had $>10^{\circ}$ of genu flexum/recurvatum. Those patients who had uncorrectable varus/valgus deformity of their knee were 4 times more likely to perceive unequal leg length. These malalignment or torsional deformities can be easily found during the physical examination, but these conditions are usually missed during clinic visits because orthopedic surgeons simply do not evaluate patients in standing position, while walking, or while wearing examination gown or shorts (instead of street clothes). Many orthopedic surgeons might be cautious in asking their patients about their perception of limb length because this may trigger concerns about postoperative limblength discrepancy. It is important to inform patients about the normal differences in leg length in the general healthy population and discuss the other factors that can affect the perception of the leg length, such as disorders of the spine or other lower extremity joints.

\section{Table 4}

Interobserver Agreement Results From Bland and Altman Test for Two-Dimensional (2D) Images.

\begin{tabular}{lccc}
\hline 2D Parameters & ICC & 95\% Confidence & $\begin{array}{c}\text { Interreader } \\
\text { Agreement } \\
\text { (Bland-Altman) }\end{array}$ \\
\hline Femoral length $(\mathrm{mm})$ & 0.99 & $0.9989-0.9994$ & $0.0 \pm 2.3$ \\
Tibial length $(\mathrm{mm})$ & 0.99 & $0.9990-0.9995$ & $0.1 \pm 2.1$ \\
Anatomic length $(\mathrm{mm})$ & 0.99 & $0.9995-0.9997$ & $0.2 \pm 3.0$ \\
Functional length $(\mathrm{mm})$ & 0.99 & $0.9993-0.9996$ & $0.0 \pm 3.5$ \\
Femoral mechanical angle $\left(^{\circ}\right)$ & 0.97 & $0.9639-0.9813$ & $0.1 \pm 1.6$ \\
Tibial mechanical angle $\left(^{\circ}\right)$ & 0.91 & $0.8768-0.9349$ & $-0.1 \pm 2.8$ \\
HKS $\left(^{\circ}\right)$ & 0.99 & $0.9880-0.9938$ & $-0.02 \pm 0.49$ \\
Flexum/recurvatum $\left(^{\circ}\right)$ & 0.99 & $0.9989-0.9994$ & $-0.03 \pm 0.90$ \\
Hip-knee-ankle angle $\left(^{\circ}\right)$ & 0.99 & $0.9984-0.9992$ & $-0.07 \pm 0.53$ \\
\hline
\end{tabular}

HKS, Hip-Knee-Shaft angle; ICC, interclass correlation coefficient.
Table 5

Interobserver Agreement Results From Bland and Altman Test for ThreeDimensional (3D) Images.

\begin{tabular}{lccc}
\hline 3D Parameters & ICC & 95\% Confidence & $\begin{array}{l}\text { Interobserver } \\
\text { Agreement } \\
\text { (Bland-Altman) }\end{array}$ \\
\hline Femoral length $(\mathrm{mm})$ & 0.99 & $0.9982-0.9991$ & $0.0 \pm 2.9$ \\
Tibial length $(\mathrm{mm})$ & 0.99 & $0.9978-0.9989$ & $-0.1 \pm 3.0$ \\
Anatomic length $(\mathrm{mm})$ & 0.99 & $0.9991-0.9995$ & $-0.2 \pm 3.7$ \\
Functional length $(\mathrm{mm})$ & 0.99 & $0.9994-0.9997$ & $-0.3 \pm 2.9$ \\
Femoral mechanical angle $\left(^{\circ}\right)$ & 0.95 & $0.9432-0.9705$ & $0.1 \pm 1.6$ \\
Tibial mechanical angle $\left(^{\circ}\right)$ & 0.92 & $0.8985-0.9466$ & $-0.1 \pm 2.9$ \\
HKS $\left(^{\circ}\right.$ ) & 0.97 & $0.9663-0.9826$ & $-0.01 \pm 0.64$ \\
Flexum/recurvatum $\left(^{\circ}\right)$ & 0.99 & $0.9986-0.9993$ & $-0.0 \pm 1.0$ \\
Hip-knee-ankle angle $\left(^{\circ}\right)$ & 0.99 & $0.9963-0.9981$ & $-0.01 \pm 0.82$ \\
\hline
\end{tabular}

HKS, Hip-Knee-Shaft angle; ICC, interclass correlation coefficient.

\section{Limitations}

Our study has some shortcomings. The subjects did not have any hip or knee arthroplasties but were evaluated for hip or knee degenerative joint disease and treated nonoperatively. It would have been informative to assess the patients for limb-length discrepancy after arthroplasty surgery. We also assessed the correctability of the varus/valgus deformity by physical examination instead of radiograph to limit radiation exposure to the patient and surgeon. Although an experienced senior surgeon performed all measurements, there is still the possibility of inaccurate measurements. In addition, our study did not consider foot and ankle deformities.

\section{Conclusions}

The patient perception of limb length can be better correlated with the knee varus/valgus and flexum/recurvatum deformity and their correctability than with the objective anatomical lengths of the femur and tibia. This study opens new perspectives for better understanding of true and apparent limb-length discrepancy and improving the evaluation of medical legal issues after joint arthroplasty or trauma surgeries. This can help orthopedic surgeons in discussions of the causes of the apparent limb-length discrepancy with their patients. This study also emphasizes the importance of 3D measurements in outlier cases, such as severe varus or valgus deformity and severe genu flexum/recurvatum of the knee. Most of these outliers can be recognized with a thorough physical examination in standing position.

\section{References}

1. Blackley HR, Howell GE, Rorabeck CH. Planning and management of the difficult primary hip replacement: preoperative planning and technical considerations. Instr Course Lect 2000;49:3.

2. Edeen J, Sharkey PF, Alexander AH. Clinical significance of leg-length inequality after total hip arthroplasty. Am J Orthop (Belle Mead NJ) 1995;24(4):347.

3. Matsuyama Y, Hasegawa Y, Yoshihara H, et al. Hip-spine syndrome: total sagittal alignment of the spine and clinical symptoms in patients with bilateral congenital hip dislocation. Spine (Phila Pa 1976) 2004;29(21):2432.

4. McCrory JL, White SC, Lifeso RM. Vertical ground reaction forces: objective measures of gait following hip arthroplasty. Gait Posture 2001;14(2):104.

5. Austin MS, Hozack WJ, Sharkey PF, et al. Stability and leg length equality in total hip arthroplasty. J Arthroplasty 2003;18(3 Suppl 1):88.

6. Hofmann AA, Skrzynski MC. Leg-length inequality and nerve palsy in total hip arthroplasty: a lawyer awaits! Orthopedics 2000;23(9):943.

7. Parvizi J, Sharkey PF, Bissett GA, et al. Surgical treatment of limb-length discrepancy following total hip arthroplasty. J Bone Joint Surg Am 2003:85-A(12):2310.

8. Pritchett JW. Nerve injury and limb lengthening after hip replacement: treatment by shortening. Clin Orthop Relat Res 2004;418:168.

9. Rand JA, Ilstrup DM. Comparison of Charnley and T-28 total hip arthroplasty. Clin Orthop Relat Res 1983;180:201. 
10. Turula KB, Friberg O, Lindholm TS, et al. Leg length inequality after total hip arthroplasty. Clin Orthop Relat Res 1986;202:163.

11. Williamson JA, Reckling FW. Limb length discrepancy and related problems following total hip joint replacement. Clin Orthop Relat Res 1978;134:135.

12. Upadhyay A, York S, Macaulay W, et al. Medical malpractice in hip and knee arthroplasty. J Arthroplasty 2007;22(6 Suppl 2):2.

13. Dubousset J, Charpak G, Dorion I, et al. A new 2D and 3D imaging approach to musculoskeletal physiology and pathology with low-dose radiation and the standing position: the EOS system. Bull Acad Natl Med 2005;189(2):287.

14. Than P, Szuper K, Somoskeoy S, et al. Geometrical values of the normal and arthritic hip and knee detected with the EOS imaging system. Int Orthop 2012;36(6):1291.

15. Friberg O. Clinical symptoms and biomechanics of lumbar spine and hip joint in leg length inequality. Spine (Phila Pa 1976) 1983;8(6):643.

16. McCaw ST, Bates BT. Biomechanical implications of mild leg length inequality. Br J Sports Med 1991;25(1):10.

17. Reid DC, Smith B. Leg length inequality: a review of etiology and management. Physiother Can 1984;36(4):177.

18. Kraus VB, Vail TP, Worrell T, et al. A comparative assessment of alignment angle of the knee by radiographic and physical examination methods. Arthritis Rheum 2005;52(6):1730.

19. Gurney B. Leg length discrepancy. Gait Posture 2002;15(2):195.

20. Maloney WJ, Keeney JA. Leg length discrepancy after total hip arthroplasty. J Arthroplasty 2004;19(4 Suppl 1):108.

21. Mannello DM. Leg length inequality. J Manipulative Physiol Ther 1992;15(9): 576.

22. Wylde V, Whitehouse SL, Taylor AH, et al. Prevalence and functional impact of patient-perceived leg length discrepancy after hip replacement. Int Orthop 2009;33(4):905.
23. Guichet JM, Spivak JM, Trouilloud P, et al. Lower limb-length discrepancy. An epidemiologic study. Clin Orthop Relat Res 1991;272:235.

24. Knutson GA. Anatomic and functional leg-length inequality: a review and recommendation for clinical decision-making. Part I, anatomic leg-length inequality: prevalence, magnitude, effects and clinical significance. Chiropr Osteopat 2005;13:11.

25. Knutson GA. Anatomic and functional leg-length inequality: a review and recommendation for clinical decision-making. Part II. The functional or unloaded leg-length asymmetry. Chiropr Osteopat 2005;13:12.

26. Specht DL, De Boer KF. Anatomical leg length inequality, scoliosis and lordotic curve in unselected clinic patients. J Manipulative Physiol Ther 1991;14(6):368.

27. Beattie P, Isaacson K, Riddle DL, et al. Validity of derived measurements of leglength differences obtained by use of a tape measure. Phys Ther 1990;70(3):150.

28. Cleveland RH, Kushner DC, Ogden MC, et al. Determination of leg length discrepancy. A comparison of weight-bearing and supine imaging. Invest Radiol 1988;23(4):301.

29. Gross RH. Leg length discrepancy in marathon runners. Am J Sports Med $1983 ; 11(3): 121$.

30. Mincer AE, Cummings GS, Andrew PD, et al. Effect of leg length discrepancy on trunk muscle fatigue and unintended trunk movement. J Phys Ther Sci 1997;9(1):1.

31. Soukka A, Alaranta $H$, Tallroth $K$, et al. Leg-length inequality in people of working age. The association between mild inequality and low-back pain is questionable. Spine (Phila Pa 1976) 1991;16(4):429.

32. Stevens PM. Radiographic distortion of bones: a marker study. Orthopedics 1989;12(11):1457.

33. Thelen P, Delin C, Folinais D, et al. Evaluation of a new low-dose biplanar system to assess lower-limb alignment in 3D: a phantom study. Skeletal Radiol 2012;41(10):1287. 